\title{
QUALIDADE FISIOLÓGICA DE SEMENTES DE MILHO NA PRESENÇA DE BIOESTIMULANTES
}

\author{
Physiological quality of corn seeds in the presence of biostimulants
}

\author{
Tanismare Tatiana de Almeida Silva ${ }^{1}$, Édila Vilela de Rezende Von Pinho², Deisy Lúcia Cardoso ${ }^{3}$, \\ Clarissa Alves Ferreira ${ }^{4}$, Patrícia de Oliveira Alvim ${ }^{4}$,Aldo Augusto Fernades da Costa ${ }^{5}$
}

\begin{abstract}
RESUMO
Os reguladores de crescimento podem influenciar na qualidade fisiológica das sementes assim como na atividade de enzimas envolvidas na germinação. Podem ainda apresentar em suas formulações micronutrientes que atuam principalmente como catalisadores de enzimas. Nesta pesquisa sementes de milho híbrido da cultivar GNZ 2004, e da linhagem Le 57 foram tratadas com os seguintes bioestimulantes e dosagens: 1 .Stimulate ${ }^{\circledR} 12,5 \mathrm{~mL} / \mathrm{kg}$ de sementes, 2.Cellerate ${ }^{\circledR} 10,0 \mathrm{~mL} / \mathrm{kg}, 3$. mistura de Cellerate ${ }^{\circledR}$ Stimulate ${ }^{\circledR}(10,0 \mathrm{~mL} /$ $\mathrm{kg}+12,5 \mathrm{~mL} / \mathrm{kg}$ ), 4. Booster $^{\circledR} 100 \mathrm{~mL} / 20 \mathrm{~kg}$ e 5.testemunha. Logo após o tratamento, as sementes foram submetidas aos testes de germinação, envelhecimento acelerado, teste de frio e emergência de plântulas. Foram avaliadas ainda a massa de matéria seca de plântulas, parte aérea e raiz e as atividades das enzimas $\alpha$-amilase, catalase, esterase e peroxidase. Nas sementes tratadas com os bioestimulantes não houve melhoria na qualidade de sementes e sob condições de estresses a utilização dos bioestimulantes Stimulate ${ }^{\circledast}+$ Cellerate $^{\circledR}$ e Cellerate ${ }^{\circledR}$ reduziu a qualidade fisiológica de sementes de milho. Menor atividade da enzima peroxidase foi observada em sementes tratadas com Stimulate ${ }^{\circledR}$, Cellerate $^{\circledR}$ e Stimulate $^{\circledR}+$ Cellerate $^{\circledR}$. Maior atividade da enzima esterase foi observada em sementes tratadas com Stimulate ${ }^{\circledR}+$ Cellerate ${ }^{\circledR}$ indicando fitotoxidez dos mesmos.
\end{abstract}

Termos para indexação: Zea mays, reguladores de crescimento, germinação.

\begin{abstract}
Growth regulators can influence the physiological quality of seeds as well as the activity of enzymes involved in germination. They may, further, present in their formulation micronutrients which act mainly as enzyme catalysts. In this research work, hybrid corn seeds of the cultivar GNZ 2004 and line Le 57 were treated with the following biostimulants and dosages: $1.5 t i m u l a t e^{\circledR} 12.5 \mathrm{~mL} / \mathrm{kg}$ of seed, 2.Cellerate ${ }^{\circledR} 10,0 \mathrm{~mL} / \mathrm{kg}, 3$.mixtue of Cellerate ${ }^{\circledR}+$ Stimulate $^{\circledR}(10.0 \mathrm{~mL} / \mathrm{kg}+12.5 \mathrm{~mL} / \mathrm{kg}), 4$. Booster $^{\circledR} 100 \mathrm{~mL} / 20 \mathrm{~kg}$ and $5 . c o n t r o l$. Soon after the treatment, the seeds were submitted to the tests of germination, accelerated ageing and cold and seedling emergence tests. In addition, mass of dry matter of seedlings, shoot and roots and the activities of the enzymes á-amylase, catalase, esterase and peroxidase were evaluated. In the biostimulant-treated seeds, there were no improvements in the quality of seeds and under stressful conditions, the use of the biostimulants Stimulate ${ }^{\circledR}+$ Cellerate $^{\circledR}$ and Cellerate ${ }^{\circledR}$ reduced the physiological quality of corn seeds. Increased activity of the peroxidase enzyme was found in seeds treated with Stimulate ${ }^{\circledR}$, Cellerate ${ }^{\circledast}$ and Stimulate ${ }^{\circledR}+$ Cellerate $^{\circledR}$. Increased activity of the enzyme esterase was observed in seeds treated with Stimulate ${ }^{\circledR}+$ Cellerate $^{\circledR}$ pointing out phytotoxicity of them.
\end{abstract}

Index terms: Zea mays, growth regulators, germination.

(Recebido em 21 de setembro de 2006 e aprovado em 16 de julho de 2007)

\section{INTRODUÇÃO}

Novas tecnologias têm sido empregadas visando incremento na produção da cultura do milho, incluindo o uso crescente de sementes melhoradas associado à aplicação via semente de fungicidas, herbicidas e reguladores de crescimento. A qualidade da semente é alcançada durante o processo de produção, devendo ser conservada até o momento da semeadura, garantindo um alto potencial de emergência de plântulas em campo e ganho em produtividade.

A aplicação de reguladores de crescimento via semente tem sido proposta por várias empresas. Esses reguladores são definidos como substâncias naturais ou sintéticas que podem ser aplicadas diretamente nas plantas, em sementes e no solo, com a finalidade de incrementar a produção e melhorar a qualidade de sementes. Entre as

\footnotetext{
'Engenheira Agrônoma, Doutoranda em Fitotecnia - Departamento de Agricultura/DAG - Universidade Federal de Lavras/UFLA - Cx. P. 3037 - $37200-000$ 37200-000 - Lavras, MG - mareagro@bol.com.br

EEngenheira Agrônoma, Doutora, Professora Associado - Departamento de Agricultura/DAG - Universidade Federal de Lavras/UFLA - Cx. P. 3037 37200-000 - 37200-000 - Lavras, MG - edila@ufla.br

${ }^{3}$ Engenheira Agrônoma, Mestranda em Genética e Melhoramento - Departamento de Fitotecnia - Universidade Estadual do Norte Fluminense Darcy Ribeiro/UENF - Avenida Alberto Lamego, 2000 - 28013-603 - Campos dos Goytacazes, RJ - deisy@hotmail.com

${ }^{4}$ Engenheiras Agrônomas, Mestrandas em Fitotecnia - Departamento de Agricultura/DAG - Universidade Federal de Lavras/UFLA - Cx. P. 3037 - $37200-000$ -

37200-000 - Lavras, MG - clarissaaf@yahoo.com.br; patríciadeoliveiraalvim@yahoo.com.br

${ }^{5}$ Engenheiro Agronômo - Agromen - Av 5, n800 - Orlandia, SP - 14620-000 - aldo@agromen.com.br
} 
várias alterações os reguladores de crescimento influenciam o metabolismo protéico, podendo aumentar a taxa de síntese de enzimas envolvidas no processo de germinação das sementes (MCDONALD \& KHAN, 1983) e ainda no enraizamento, floração, frutificação e senescência de plantas (CASTRO \& VIEIRA, 2001).

Alguns reguladores apresentam, em suas formulações, micronutrientes, eles são inseridos para minimizar problemas advindos da deficiência dos mesmos, durante os processos de germinação, desenvolvimento e produção de grãos. A importância dos micronutrientes pode ser entendida por meio das funções que exercem no metabolismo das plantas, atuando principalmente como catalisadores de várias enzimas (LOPES, 1989).

Para atuar, os reguladores devem estar em quantidades suficientes, interagirem com as proteínas receptoras, para serem reconhecidos e capturados por cada um dos grupos de células (SALISBURY \& ROSS, 1994). Segundo Castro \& Vieira (2001), as classes de reguladores vegetais reconhecidas são as auxinas, giberelinas, citocininas, retardadores e inibidores, e o etileno. A mistura de dois ou mais reguladores vegetais ou as misturas desses com outras substâncias (aminoácidos, nutrientes, vitaminas), é designada como bioestimulante.

As auxinas são produzidas nos ápices dos caules, nas raízes, nas sementes em germinação, nos meristemas de cicatrização, nas folhas novas e nos frutos, sendo as raízes mais sensíveis à ação delas. Durante o processo de germinação as auxinas estão envolvidas na permeabilidade das membranas e possuem relação direta com o crescimento de plântulas (CASTRO et al., 1985; CASTRO \& VIEIRA, 2001; ROSS, 1992).

As giberelinas têm papel chave na germinação de sementes, estando envolvidas tanto na superação da dormência como no controle de hidrólise das reservas, pela indução da síntese de novo da $\alpha$-amilase, enzima responsável pela hidrólise do amido (LEVITT, 1974). As giberelinas também estimulam o alongamento e divisão celular e atuam também em conjunto com a auxina, promovendo maior crescimento do caule de certas plantas (CASTRO et al., 1985). Já as citocininas possuem grande capacidade de promover divisão celular, principalmente quando interagem com as auxinas. Segundo Thomas (1977), citado por Vieira \& Castro (2000), as citocininas durante a germinação de sementes podem estar relacionadas com a permeabilidade de membranas.

Os reguladores de crescimento têm sido associados aos micronutrientes, no tratamento de sementes buscandose maiores valores de germinação e melhor estabelecimento de plantas no campo.

Os micronutrientes são requeridos pelas plantas em pequenas quantidades, embora a falta de qualquer um possa limitar o crescimento das plantas mesmo quando todos os outros nutrientes essenciais estejam presentes em quantidades adequadas (LOPES, 1989).

O cobre é necessário para a formação da clorofila nas plantas, cataliza vários processos no metabolismo vegetal e é necessário à promoção de diversas reações. $\mathrm{Na}$ presença do cobre a atividade das peroxidases e catalases é diminuída, acumulando nos tecidos, fenóis e peróxidos de hidrogênio (FAVARIN \& MARINI, 2000).

O molibdênio é necessário para a formação e atividade da enzima redutase do nitrato. Esse micronutriente é vital em leguminosas, pois ajuda na nodulação que, por sua vez, são indispensáveis ao processo de fixação simbiótica de nitrogênio. O zinco auxilia na síntese de substâncias que atuam no crescimento e nos sistemas enzimáticos, é essencial para a ativação de certas reações metabólicas. Participa da síntese do aminoácido triptofano, precursor do AIA (Ácido Indol Acético), um hormônio do crescimento. Na presença do zinco a enzima aldoíase catalisa a síntese de lipídios, substância de reserva das sementes (FAVARIN \& MARINI, 2000).

Diante do exposto torna-se necessário estudar os efeitos de micronutriente e de reguladores de crescimento sobre a qualidade fisiológica, na atividade de enzimas envolvidas na germinação de sementes e no estabelecimento de plantas no campo. Nesse trabalho foram avaliados os efeitos de bioestimulantes na qualidade fisiológica de sementes de milho (Zea mays L.).

\section{MATERIAL E MÉTODOS}

O trabalho foi realizado nos Laboratórios de Análises de Sementes e de Técnicas Moleculares, no Setor de Sementes do Departamento de Agricultura da Universidade Federal de Lavras, Minas Gerais.

Foram utilizadas sementes de milho hibrido da cultivar GNZ 2004, e da linhagem Le 57, pertencente a empresa GeneSeeds Recursos Genéticos em Milho Ltda.

Inicialmente, essas sementes foram classificadas, em peneira circular de crivo 19. As sementes foram tratadas com Tegran ${ }^{\circledR}$, na dosagem de $200 \mathrm{~g} / 100 \mathrm{~kg} / \mathrm{sementes}$ e posteriormente tratadas com os diferentes bioestimulantes compondo os seguintes tratamentos: 1.Stimulate ${ }^{\circledR}(12,5 \mathrm{ml} /$ $\mathrm{kg} / \mathrm{semente}), 2$.Cellerate ${ }^{\circledR}(10,0 \mathrm{ml} / \mathrm{kg}), 3$. mistura de Cellerate ${ }^{\circledR}$ + Stimulate $^{\circledR}(10,0 \mathrm{ml} / \mathrm{kg}+12,5 \mathrm{ml} / \mathrm{kg}), 4$. Booster $^{\circledR}(5,0 \mathrm{ml} / \mathrm{kg}) \mathrm{e}$ 5.testemunha. Os bioestimulantes possuem as seguintes formulações: Stimulate ${ }^{\circledR}: 0,0009 \%$ de cinetina (citocinina), $0,005 \%$ de ácido giberélico (giberelina) e 0,005\% de ácido indolbutírico (auxina); Celerate ${ }^{\circledR}: 5 \%$ de zinco e $10 \%$ de molibdênio, 0,005\% de ácido giberélico; Booster ${ }^{\circledR}: 3,0 \%$ de cobre, $2,0 \%$ de molibdênio, $0,10 \%$ de zinco, auxina e citocinina. Logo após o tratamento, as sementes foram submetidas aos testes de germinação e de vigor. 
O teste de germinação foi realizado utilizando 4 repetições de 50 sementes. A semeadura foi realizada em papel germitex e mantida em germinador à temperatura de $25^{\circ} \mathrm{C}$. Ao final do teste, no sétimo dia após a semeadura foram computadas as plântulas normais. Das plântulas normais foram separadas as partes aérea e raiz, que foram acondicionadas em saco de papel e levadas para estufa de circulação de ar a $60^{\circ} \mathrm{C}$ até massa constante, quando então se procedeu à avaliação das massas. Foram consideradas plântulas normais as que apresentavam raiz principal com tamanho superior a $9 \mathrm{~cm}$ e parte aérea maior que $5 \mathrm{~cm}$ e presença de, no mínimo, 2 raízes seminais.

O teste de envelhecimento acelerado foi realizado utilizando 4 repetições de 50 sementes, sendo distribuídas sobre tela de arame no interior de caixa "gerbox", contendo $40 \mathrm{ml}$ de água destilada. As caixas foram acondicionadas em BOD a $42^{\circ} \mathrm{C}$ por 72 horas. Após esse período as sementes foram submetidas ao teste de germinação, conforme descrito anteriormente.

O teste de frio foi realizado em bandejas contendo substrato areia + terra na proporção de $2: 1$, sendo semeadas 50 sementes por bandeja, em quatro repetições. $\mathrm{O}$ substrato foi umedecido para $70 \%$ da capacidade de retenção e as bandejas acondicionadas em câmara fria à $10^{\circ} \mathrm{C}$, durante 7 dias. Após esse período foram transferidas para câmara de crescimento com temperatura constante de $25^{\circ} \mathrm{C}$ e no final de 7 dias, avaliou-se o número de plântulas emersas.

Para a avaliação da emergência de plântulas, a semeadura foi realizada em canteiro contendo areia e terra na proporção 1:1. Foram utilizadas 4 repetições de 50 sementes. A contagem do número de plântulas emersas foi realizada diariamente até a estabilização do estande. Ao final de 12 dias, após a semeadura, avaliou-se o estande final e o Índice de Velocidade de Emergência foi calculado pela fórmula apresentada por (MAGUIRE, 1962).

Os testes realizados para avaliação da qualidade fisiológica das sementes seguiram o delineamento experimental inteiramente casualizado, com quatro repetições. Os dados foram interpretados estatisticamente por meio da análise de variância, e as médias comparadas pelo teste de Tukey, ao nível de 5\%.

Para as análises enzimáticas foi utilizada a técnica de eletroforese em gel descontínuo de poliacrilamida. Para a extração da enzima $\alpha$-amilase, as sementes foram colocadas para germinar em rolo de papel por um período de 70 horas. Decorrido esse período, as plúmulas e raízes das plântulas foram descartadas e o restante foi triturado em mortar sobre gelo, na presença de N-líquido. Para a extração, $200 \mathrm{mg}$ do pó das sementes foram ressuspendidos em $600 \mu \mathrm{l}$ do tampão de extração (Tris-HCl 0,2 M, pH 8,0 + 0,4\% de PVP). Para a extração das enzimas catalase e esterase, foram utilizados

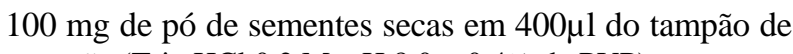
extração (Tris-HCl 0,2 M, pH 8,0 + 0,4\% de PVP).

As amostras dessas enzimas permaneceram em geladeira, incubadas no gelo por 12 horas e após esse período foram centrifugadas a $16000 \mathrm{xg}$ por 60 minutos a $4^{\circ} \mathrm{C}, 40 \mu \mathrm{l}$ do sobrenadante de cada amostra foram aplicados em géis de poliacrilamida a 4,5\% (gel concentrador) e 7,5\% (gel separador contendo $5 \%$ de amido solúvel). A corrida eletroforética foi realizada a $150 \mathrm{~V}$, durante 4 horas, utilizando-se o tampão Tris-glicina pH 8,9.

Para extração da enzima peroxidase foram utilizados $100 \mathrm{mg}$ de sementes nos quais foram adicionados $250 \mu \mathrm{de}$ tampão de extração fosfato $(0,034 \mathrm{M}$ de fosfato de sódio bi-básico, 0,2 M de sacarose, 2,56\% de PVP 40, 3M de DDT, 5,7 mM L ácido ascórbico, 2,5 mM de borato de sódio, $1 \%$ de PEG 6000, 0,002\% de $\beta$-mercaptoetanol). A mistura foi agitada em vortex e, posteriormente, mantida por uma noite em geladeira à temperatura de $4^{\circ} \mathrm{C}$, seguida de centrifugação a $16000 \mathrm{xg}$ por 60 minutos a $4^{\circ} \mathrm{C}$. Em seguida, $100 \mu \mathrm{l}$ do sobrenadante de cada amostra foram aplicados em gel de 7,5\% (gel separador) e 4,5\% ( gel concentrador). O tampão de corrida foi Tris-glicina $\mathrm{pH}$ 8,9 e a corrida eletroforética foi realizada a $4^{\circ} \mathrm{C}$, por quatro horas, a $150 \mathrm{~V}$. A revelação das enzimas foi segundo Alfenas et al. (1991).

\section{RESULTADOS E DISCUSSÃO}

Os dados de germinação e de vigor das sementes da linhagem Le 57 estão apresentados na Tabela 1. Maiores valores de germinação foram alcançados quando as sementes foram tratadas com o produto Cellerate ${ }^{\circledR} \mathrm{e}$ menores quando as sementes foram tratadas com o produto Stimulate ${ }^{\circledR}$ e Cellerate ${ }^{\circledR}+$ Stimulate $^{\circledR}$.

Para o teste de envelhecimento acelerado em sementes tratadas com Stimulate ${ }^{\circledR}$, Cellerate $^{\circledR}$ e Stimulate $^{\circledR}+$ Cellerate $^{\circledR}$ foram observados maiores índices de vigor em relação àquelas que foram tratadas com Booster ${ }^{\circledR}$ e a testemunha.

No teste de frio não houve diferença estatística entre os valores observados, em sementes tratadas com o Cellerate $^{\circledR}$, Booster $^{\circledR}$ e a testemunha. No entanto, houve redução do vigor nas sementes tratadas com Stimulate ${ }^{\circledR} \mathrm{e}$ Stimulate ${ }^{\circledR}+$ Cellerate $^{\circledR}$. Provavelmente houve efeito fitotóxico desses produtos nas condições do teste de frio.

Também foi observada redução no índice de velocidade de emergência das plântulas, quando as sementes foram tratadas com a mistura dos produtos Stimulate $^{\circledR}+$ Cellerate $^{\circledR}$. Menor valor de matéria seca da parte aérea de plântulas foi observado quando as sementes foram tratadas com o Cellerate ${ }^{\circledR}$ quando comparado à testemunha. Vale ressaltar que, na formulação desse produto, existem os micronutrientes zinco e molibdênio, e eles podem estar exercendo um efeito fitotóxico. Os 
micronutrientes quando aplicados em concentrações superiores à necessidade das plantas, podem afetar o crescimento e metabolismo delas. Quanto aos valores de peso seco da raiz e peso total de plântulas não foi observada diferença estatística, entre os tratamentos testados.

A aplicação dos bioestimulantes Cellerate ${ }^{\circledR} \mathrm{e}$ Booster $^{\circledR}$ nas sementes híbridas GNZ 2004 proporcionou um aumento nos valores de germinação quando comparadas aos observados na testemunha (Tabela 2). Segundo Castro \& Vieira (2001) a aplicação de bioestimulantes como o Stimulate $^{\circledR}$ em sementes mostrou-se eficiente no desempenho do processo germinativo, proporcionando maior número de plântulas normais e reduzindo significativamente as anormalidades de plântulas.

Os valores observados no teste de germinação considerados baixos podem ser atribuídos aos critérios utilizados durante a avaliação das plântulas normais. Muitas plântulas, nesse teste, poderiam ser consideradas como normais seguindo as Regras para a análise de sementes (BRASIL, 1992), porém elas não atendiam aos padrões definidos e descritos na metodologia.

Menores índices de velocidade de emergência de plântulas foram observados quando as sementes do híbrido GNZ 2004 foram tratadas com os produtos Cellerate ${ }^{\circledR}$ e Booster ${ }^{\circledR}$, ambos apresentam em suas formulações micronutrientes (Tabela 3). Em níveis excedentes, esses micronutrientes podem afetar o crescimento e metabolismo das plantas. Pelos resultados observados nos valores de matéria seca do sistema radicular, parte aérea, matéria seca total das plântulas, a aplicação de bioestimulantes não apresentou vantagens sobre a testemunha Sendo que de uma maneira geral, houve redução nesses valores quando as sementes foram tratadas com Cellerate ${ }^{\circledR}$ e a mistura de Stimulate $^{\circledR}+$ Cellerate $^{\circledR}$.

Tabela 1 - Resultados médios de germinação, envelhecimento acelerado (Env. Acel.), teste de frio, índice de velocidade de emergência (IVE) e peso seco parte aérea (PSPA) da Linhagem Le 57 de milho tratadas com diferentes produtos.

\begin{tabular}{lllllll}
\hline \multicolumn{1}{c}{ Linhagem } & Germinação & Env. Acel. & Teste frio & IVE & PSPA \\
\hline Stimulate ${ }^{\circledR}$ & $23,00 \mathrm{c}$ & $45,00 \mathrm{a} \mathrm{b} \mathrm{c}$ & $20,00 \mathrm{~b}$ & $10,71 \mathrm{a}$ & $0,545 \mathrm{a} \mathrm{b}$ \\
Cellerate ${ }^{\circ}$ & $59,00 \mathrm{a}$ & $49,00 \mathrm{a} \mathrm{b}$ & $39,00 \mathrm{a}$ & $10,22 \mathrm{a}$ & $0,497 \quad \mathrm{~b}$ \\
Cell® + Sti® & $32,00 \mathrm{~b} \mathrm{c}$ & $53,00 \mathrm{a}$ & $9,00 \mathrm{c}$ & $9,08 \mathrm{~b}$ & $0,536 \mathrm{a} \mathrm{b}$ \\
Booster & $40,00 \mathrm{~b}$ & $35,00 \mathrm{c}$ & $35,00 \mathrm{a}$ & $10,76 \mathrm{a}$ & $0,539 \mathrm{a} \mathrm{b}$ \\
Testemunha & $37,00 \mathrm{~b}$ & $40,00 \mathrm{~b} \mathrm{c}$ & $31,00 \mathrm{a}$ & $10,22 \mathrm{a}$ & $0,555 \mathrm{a}$ \\
\hline
\end{tabular}

As médias seguidas pela mesma letra na coluna não diferem entre si pelo teste de Tukey a 5\% significância .

Tabela 2 - Resultados médios de germinação, envelhecimento acelerado (Env. Acel.) e teste de frio do Híbrido GNZ 2004 tratadas com diferentes produtos.

\begin{tabular}{llll}
\hline \multicolumn{1}{c}{ Híbrido } & Germinação & Env. Acel. & Teste frio \\
\hline Stimulate ${ }^{\circledR}$ & $63,00 \mathrm{a} \mathrm{b}$ & $96,00 \mathrm{a}$ & $67,00 \mathrm{~b}$ \\
Cellerate ${ }^{\circledR}$ & $75,00 \mathrm{a}$ & $93,00 \mathrm{a}$ & $75,00 \mathrm{~b}$ \\
Cell® + Sti® & $64,00 \mathrm{a} \mathrm{b}$ & $86,00 \mathrm{~b}$ & $52,00 \mathrm{c}$ \\
Booster ${ }^{\circledR}$ & $78,00 \mathrm{a}$ & $94,00 \mathrm{a}$ & $95,00 \mathrm{a}$ \\
Testemunha & $49,00 \mathrm{~b}$ & $95,00 \mathrm{a}$ & $87,00 \mathrm{a}$ \\
\hline
\end{tabular}

As médias seguidas pela mesma letra na coluna não diferem entre si pelo teste de Tukey, a 5\% de significância.

Tabela 3 - Resultados médios de índice de velocidade de emergência (IVE), peso seco de raíz (PSSR), peso seco de parte aérea (PSPA) e peso total do Híbrido GNZ 2004 tratadas com diferentes produtos.

\begin{tabular}{|c|c|c|c|c|}
\hline Híbrido & IVE & PSSR & PSPA & Peso Total \\
\hline Stimulate $®$ & $12,27 \mathrm{a}$ & $0,312 \mathrm{ab}$ & $0,670 \mathrm{a} \mathrm{b}$ & $0,982 \mathrm{ab}$ \\
\hline Cellerate ${ }^{\circledR}$ & $11,12 \quad \mathrm{c}$ & $0,285 \quad b c$ & $0,647 \quad b c$ & $0,928 \quad \mathrm{bc}$ \\
\hline Cell $\AA+$ Sti ${ }^{\circledR}$ & $12,36 \mathrm{a}$ & $0,267 \quad c$ & $0,613 \quad \mathrm{c}$ & 0,880 \\
\hline Booster ${ }^{\circledR}$ & $11,39 \quad \mathrm{bc}$ & $0,320 \mathrm{a} \mathrm{b}$ & $0,696 \mathrm{a}$ & $1,016 \mathrm{a}$ \\
\hline Testemunha & $12,09 \mathrm{a} \mathrm{b}$ & $0,331 \mathrm{a}$ & $0,672 \mathrm{a} \mathrm{b}$ & $1,000 \mathrm{a}$ \\
\hline
\end{tabular}

As médias seguidas pela mesma letra na coluna não diferem entre si pelo teste de Tukey, a 5\% de significância . 
Nas características ligadas ao desenvolvimento das plântulas, a mistura dos produtos Cellerate ${ }^{\circledR}+$ Stimulate $^{\circledR}$ pode estar apresentando efeito fitotóxico sobre a semente. Nas sementes tratadas com esses produtos foram observados os menores valores de vigor pelos testes de envelhecimento acelerado e teste de frio. $\mathrm{O}$ produto Cellerate $^{\circledR}$ tem em sua formulação $5 \%$ de zinco e $10 \%$ de molibdênio. $\mathrm{O}$ zinco apesar de ser um micronutriente essencial, pode afetar o crescimento e metabolismo normal de espécies vegetais, quando presente em níveis excedentes no ambiente (MARSCHNER, 1995). Nas sementes submetidas a esse tratamento, também foi observado aumento na atividade da enzima esterase (Figura 1A). O tratamento com essa mistura pode ter acelerado os processos de deterioração, uma vez que essa enzima está associada à deterioração em sementes (MCDONALD 1999). Os padrões dessa enzima foram semelhantes em sementes das linhagens submetidas aos diferentes tratamentos.

Para a enzima $\alpha$-amilase (Figura 1B), houve menor atividade em sementes submetidas aos tratamentos com Stimulate $^{\circledR}$ e Booster ${ }^{\circledR}$. Analisando o padrão enzimático dessa enzima em sementes híbridas foi observado o mesmo padrão entre tratamentos. Comparando os padrões observados em sementes do híbrido e da linhagem, observa-se menor atividade em sementes da linhagem, sugerindo que, por apresentarem menores teores de giberelina, sementes de linhagem também apresentam menor atividade da $\alpha$-amilase. Essa maior atividade pode estar associada aos maiores valores de germinação observados em sementes das linhagens tratadas com Cellerate $^{\circledR}$ (Tabela 1). Esse produto apresenta em sua composição 0,005\% de ácido giberélico. De acordo com Rood et al. (1983, 1990) existe uma correlação positiva entre heterose e teor de giberelina, sendo que o teor de giberelina nas plântulas hibridas é significativamente maior que nas de suas linhagens parentais.

A enzima $\alpha$-amilase está envolvida no principal sistema de degradação do amido. Sendo assim, o embrião produz o $\mathrm{GA}_{3}$ que é transportado até a camada de aleurona, estimulando a síntese de hidrólises que são secretadas para o endosperma onde, juntamente com outras enzimas que são reativadas e ou sintetizadas de novo, irão degradar o amido (NENDEL et al., 1996).

A esterase (Figura 1A) é uma enzima envolvida em reações de hidrólise de ésteres. Avaliando a atividade de esterases, durante a deterioração de sementes de amendoim, Aung \& McDonald (1995), observaram decréscimo na sua atividade total, com o aumento de deterioração tanto em sementes embebidas como não embebidas. Esse grande grupo de enzimas hidrolíticas libera ácidos graxos dos lipídeos, que são usados na $\beta$ oxidação, como fonte de energia para os eventos germinativos. Enquanto muitos desses lipídeos são provenientes de lipossomos, alguns são constituintes de membranas, cuja degradação aumenta com a deterioração. Segundo Menezes (2005), padrões isoenzimáticos de esterase apresentam-se polimórficos em sementes de cultivares de milho com diferentes níveis de qualidade fisiológica.

Em relação à enzima peroxidase (Figura 1C) observou-se um decréscimo na intensidade das bandas, em sementes da linhagem tratadas com Stimulate ${ }^{\circledR}$, Cellerate ${ }^{\circledR}$, Stimulate ${ }^{\circledR}+$ Cellerate $^{\circledR}$, quando comparada com a da testemunha. Menor atividade dessa enzima foi observada em sementes tratadas com Stimulate $^{\circledR}+$ Cellerate $^{\circledR}$. Em sementes hibridas maior atividade dessa enzima foi observada também em sementes tratadas com Stimulate ${ }^{\circledR}+$ Cellerate ${ }^{\circledR}$. Constatou-se também uma nova banda quando as sementes híbridas foram tratadas com Cellerate ${ }^{\circledR}$. Essa enzima é removedora de peróxido e a perda de sua atividade pode tornar a semente mais sensível aos efeitos de $\mathrm{O}_{2}$ e radicais livres sobre ácidos graxos insaturados de membrana, o que provoca a degeneração de suas membranas e o comprometimento de seu vigor. As peroxidases desempenham um papel crítico no metabolismo das plantas e na oxidação por peróxidos, como aceptores de hidrogênio, sendo importante nos mecanismos de defesa (FARIA et al., 2003).

Com a menor atividade da enzima peroxidase, em sementes tratadas com Stimulate ${ }^{\circledR}+$ Cellerate $^{\circledR}$, espera-se maior sensibilidade aos efeitos de $\mathrm{O}_{2}$ e de radicais livres, o que parece ter interferido nos valores de germinação e de vigor das sementes submetidas aos referidos tratamentos.

Não houve diferenças nos padrões eletroforéticos para a catalase em sementes submetidas aos diferentes tratamentos (Figura 1D). A catalase é uma enzima capaz de realizar a desintoxição de $\left(\mathrm{O}_{2}^{-}\right)$e $\mathrm{H}_{2} \mathrm{O}_{2}$ (BAILLY et al., 2002; MCDONALD, 1999). O peróxido de hidrogênio gerado é decomposto principalmente pela catalase, cujas subunidades são formadas no citoplasma, sendo a síntese completada no peroxissomo. Em outros compartimentos subcelulares, o peróxido de hidrogênio é removido pelas peroxidases (MCDONALD, 1999). 


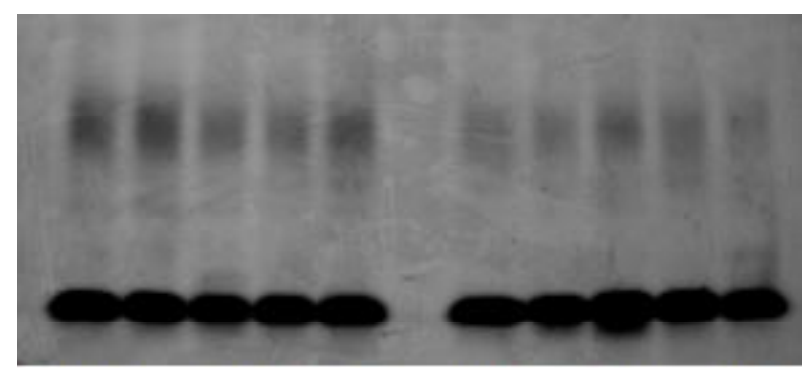

L1 $\quad$ L2 $\quad$ L3 $\quad$ L4 $\quad$ L5

Figura 1A - Enzima Esterase

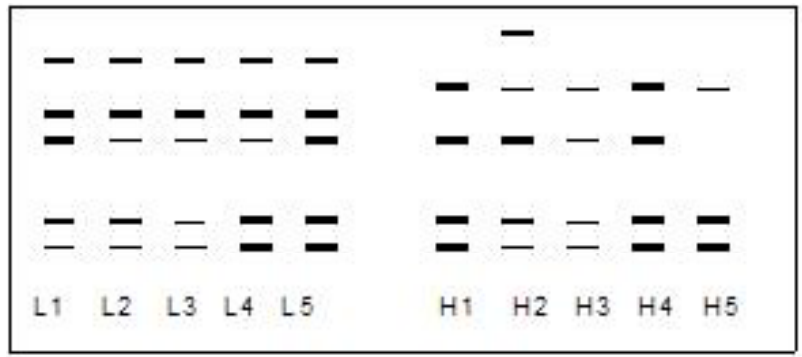

Figura 1C-Enzima Peroxidase.

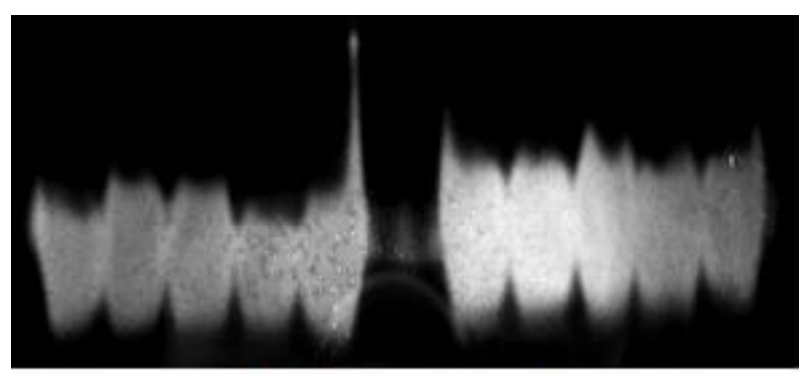

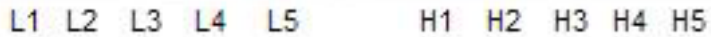

Figura 1B - Enzima $\alpha$ amilase.

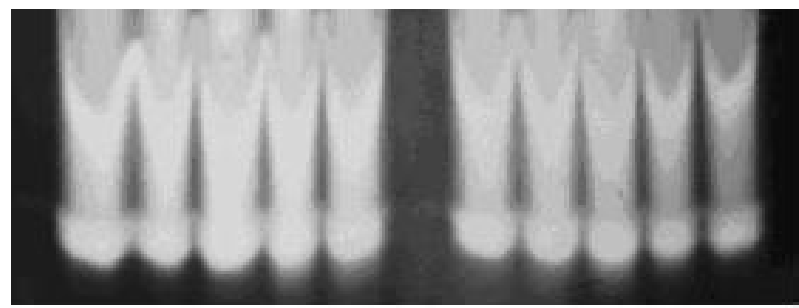

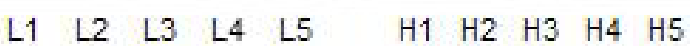

Figura 1D - Enzima Catalase

Figuras 1A, 1B, 1C, 1D - Padrões isoenzimáticos em sementes de milho submetidas aos tratamentos: Stimulate ${ }^{\circledR}$ (1), Cellerate $^{\circledR}$ (2), Cell $^{\circledR}+\operatorname{Stim}^{\circledR}$ (3), Booster ${ }^{\circledR}$ (4), Testemunha (5); sendo L (Linhagem) e H (Híbrido).

\section{CONCLUSÕES}

Não houve melhoria da qualidade de sementes quando elas foram submetidas a tratamento com bioestimulantes.

Os produtos utilizados interferiram nos sistemas enzimáticos, durante o processo de germinação.

Sob condições de estresses a utilização dos bioestimulantes Stimulate ${ }^{\circledR}+$ Cellerate $^{\circledR}$ e Cellerate ${ }^{\circledR}$ parecem reduzir a qualidade fisiológica de sementes de milho.

\section{REFERÊNCIAS BIBLIOGRÁFICAS}

ALFENAS, A. C.; PETRES, I.; BRUCE, W.; PASSADOS, G. C. Eletroforese de proteínas e isoenzimas de fungos e essências florestais. Viçosa: UFV, 1991. 242 p.

AUNG, U. T.; MCDONALD, M. B. Changes in esterase activity associated with peanut (Arachis hipogaea L.) seed deterioration. Seed Science and Technology, Zurich, v. 23, n. 1, p. 101-111, 1995.

BAILLY, C.; BOGATEK-LESZCZYNSKA, R.; CÔME, D.; CORBINEAU, F. Changes in activities of antioxidant enzymes and lipoxygenase during growth of sunflower seedlings from seeds of diferent vigour. Seed Science Research, Wallingford, v. 12, n. 1, p. 47-55, Mar. 2002.

BRASIL. Ministério da Agricultura e da Reforma Agrária. Regras para análise de sementes. Brasília, DF: SNDA/ DNDV/CLAV, 1992. 365 p.

CASTRO, P. R. C.; GONÇALVES, M. B.; DEMÉTRIO, C. G. B. Efeito dos reguladores vegetais na germinação de sementes. Anais da Esalq, Piracicaba, v. 2, p. 449-468, 1985.

CASTRO, P. R. C.; VIEIRA, E. L. Aplicações de reguladores vegetais na agricultura tropical. Guaíba: Livraria e Editora Agropecuária, 2001. 132 p.

FARIA, M. A. V. de R.; PINHO, R. G. von; PINHO, E. V. de R. von; GUIMARÃES, R. M. Marcadores moleculares da qualidade de fisiológica das sementes. Lavras: UFLA/FAEPE, 2003.

FAVARIN, J. L.; MARINI, J. P. Importância dos micronutrientes para a produção de grãos. Rio de Janeiro, 2000. Disponível em: <http://www.snagricultura.org.br/ artigos/artitec-micronutrientes.htm>. Acesso em: 25 mar. 2006. 
LEVITT, J. Introduction to plant physiology. 2. ed. Saint Louis: The C.V. Mosby, 1974. 447 p.

LOPES, A. S. Manual de fertilidade do solo. Traduzido por Alfredo Scheid Lopes. São Paulo: ANDA/Fotapos, 1989.

MAGUIRE, J. D. Seed of germination and relation evaluation for seedling emergence vigor. Crop Science, Madison, v. 2, p. 176-177, 1962.

MARSCHNER, H. Mineral nutrition of higher plants. 2. ed. San Diego: Academic, 1995. 902 p.

McDONALD, M. B. Seed deterioration: physiology, repair and assessment. Seed Science and Technology, Zürich, v. 27, n. 1, p. 177-237, 1999.

McDONALD, M. D.; KHAN, A. A. Acid scarification and protein synthesis during seed germination. Agronomy Journal, Madison, v. 2, n. 75, p. 111-114, 1983.

MENEZES, M. Identificação de cultivares de milho, feijão, algodão e soja por meio de enzimas e de proteínas resistentes ao calor. 2005. 92 p. Dissertação (Mestrado em Fitotecnia) - Universidade Federal de Lavras, Lavras, 2005.
NENDEL, J. L.; ASSIS, F. N. de; CARMONA, P. S. A planta de arroz: morfologia e fisiologia. Pelotas: UFPEL, 1996. 56 p.

ROOD, S. B.; BLAKE, T. J.; PHARIS, R. P. Gibberellins and heterosis in maize: II. response to gibberellic acid and metabolism of 3H GA20. Plant Physiology, Maryland, v. 71, n. 3, p. 645-651, 1983.

ROOD, S. B.; BUZZELI, R. I.; MAJOR, D. J.; PHARIS, R. P. Gibberellins and heterosis in maize: quantitative relationships. Crop Science, Madison, v. 30, n. 2, p. 281286, 1990.

ROSS, C. W. Hormones and growth regulators: auxins and gibberellins. In: SALISBURY, F. B.; ROSS, C. W. (Eds.). Plant physiology. 4. ed. Belmond: Wadsworth, 1992. p. 357-377.

SALISBURY, F. B.; ROSS, C. W. Fisiologia vegetal. Traduzido por V. G. Velázquez. Mexico: Iberoamérica, 1994. 759 p.

VIEIRA, E. L.; CASTRO, P. R. C. Ação de Stimulate na germinação de sementes, vigor de plântulas e crescimento radicular de plantas de milho (Zea mays L.). Piracicaba: Esalq-USP, 2000. 15 p. (Relatório técnico). 